\title{
Percursos alternativos - o Parkour enquanto fenómeno (sub)cultural
}

\author{
Rui Gonçalves de Carvalho \\ Ana Luísa Pereira
}

https://doi.org/10.5628/rpcd.08.03.427

\author{
Universidade do Porto \\ Faculdade de Desporto \\ Portugal
}

\section{RESUMO}

Com este trabalho, propusemo-nos analisar um grupo de praticantes de parkour para tentar entender se se constituem, ou não, como parte de uma subcultura. Recorremos à observação participante como meio de obter a informação que necessitávamos, complementando com entrevistas semi-estruturadas. Os dados daqui recolhidos foram submetidos à análise de conteúdo, da qual surgiu o nosso sistema categorial. Este foi constituído pelas seguintes categorias: i) Ideologia, ii) Resistência Social, iii) Construção da identidade, iv) Simbologia e estética, v) Independência face ao espaço global e vi) Relação com o espaço de prática. Como principais conclusões, podemos dizer, que no parkour encontrámos uma identidade própria; um carácter de resistência social que se manifesta especialmente na luta por um espaço de expressão; uma dinâmica de grupo com normas e valores próprios; uma estética relacionada, com a forma como o espaço é explorado e com a funcionalidade do vestuário; um afastamento face à evolução do panorama global e, uma nova forma de relação com o espaço urbano.

Palavras-chave: parkour; free-running, subcultura, desportos alternativos urbanos

\begin{abstract}
Alternative paths - the parkour as a (sub)cultural phenomenon

Through this work, we proposed to analyse a group of urban alternative sports participants to try to understand if they are, or not, a part of a subculture. Our data was collected throughout participant observation as a means to obtain the information and was complemented with semi-structured interviews. These data were submitted to content analysis, from which resulted our categorical system. The categories for analysis were: i) Ideology; ii) Social Resistance; iii) Identity construction; iv) Symbology and aesthetics; v) Independency from global space and vi) Relationship with space of practice. We concluded that parkour has a unique ideology; a group dynamics with it's own rules and conducts; an aesthetic related to the way it explores the space of practice on one hand, and with functionality of the clothes worn, on the other hand, a sense of independence towards the evolution of the global scene; and a new way of relating to urban space.
\end{abstract}

Key-words: parkour; free-running; subculture; urban alternative sports 


\section{INTRODUÇÃOO}

O desporto é um espaço de relação e de prática, sendo, frequentemente, percebido como uma forma de manter a posição dos grupos dominantes, através do reforço e reprodução, das relações sociais típicas do capitalismo, i.e., como um meio de reprodução das normas e valores culturais dominantes. Mais recentemente, o desporto começou também a ser visto como um fenómeno onde estes valores e normas são desafiados através de formas desportivas alternativas. São novos modos de prática que surgem e que levantam a necessidade de compreensão da cultura e dos sentidos das práticas dos seus participantes. Exemplo disso é o parkour, que parece estar a quebrar barreiras ao nível da sua representação nos meios de comunicação, aumentando significativamente a sua popularidade. De repente, o parkour está em todo o lado, mas a sua popularidade não significa que seja compreendido.

O facto de, do ponto de vista sociológico, o parkour se apresentar como uma página em branco foi o incentivo para iniciar um estudo a este nível. A questão que se colocou foi a seguinte: Que características permitem falar de um desporto enquanto subcultura e de que forma estas se manifestam no parkour? Procurámos, então, compreender melhor este desporto e a sua relação com o espaço envolvente, de forma a: i) entender quais as características que permitem falar de um desporto enquanto subcultura; ii) analisar o parkour no contexto das subculturas urbanas; iii) identificar que características de uma subcultura se manifestam no parkour. Através de uma pesquisa etnográfica com um grupo de praticantes de parkour, este artigo providencia um estudo de caso de uma actividade com crescente popularidade, evidenciando a importância da observação participante na compreensão dos desportos alternativos enquanto subculturas. Esta análise foi realizada à luz da cultura urbana, visto que a cidade, com a sua "teatralidade", se constitui como objecto de especial ritualização, como forma de apropriação por parte de todos(15). Começamos por uma abordagem ao conceito de subcultura, demonstrando que, apesar de algumas discussões, é uma ferramenta útil para a compreensão de práticas como o parkour.

Adicionalmente, apresentamos os elementos que nos permitem distinguir as diferentes subculturas.
Entretanto apresentamos a metodologia, para então nos debruçarmos sobre o parkour como uma expressão de subcultura urbana.

\section{Subculturas}

O uso do conceito de subcultura não tem sido consensual, existindo inúmeras discussões em torno da sua utilização como forma de categorizar a formação e desenvolvimento de grupos, de jovens ou não. Dizemos de jovens, pois terá sido a partir destes que este conceito se difundiu e também por ter sido a partir destes que a sua utilização se poderá questionar. Apesar do conceito de subcultura ser, actualmente, algo problemático no estudo da juventude, pode ser uma ferramenta conceptual útil em contextos como o desporto, onde a pertença subcultural não se restringe a grupos 'juvenis'.

O primeiro conjunto de trabalhos coerente no âmbito das subculturas foi desenvolvido pela Escola de Chicago entre 1920 e 1940, mas terá sido em Inglaterra, nos anos 60 e 70, que uma abordagem explicitamente subcultural se desenvolveu no estudo das classes juvenis trabalhadoras no Centro Contemporâneo de Estudos Culturais (Center for Contemporary Cultural Studies - CCCS). Para este grupo de trabalho, a participação numa subcultura já não era compreendida como desviante, mas como uma forma de resistência que reflectia lutas de classes mais vastas. O objectivo do CCCS era o de explicar a emergência das subculturas juvenis no pós II Guerra Mundial na Grã-Bretanha( ${ }^{(27)}$. Desde então, os debates em torno do significado de subcultura têm sido abundantes, mas tem sido, sobretudo, durante a última década, que a ideia de subcultura como conceito teórico e ferramenta analítica tem sido alvo de discussão. Este debate tem prevalecido no âmbito dos estudos da juventude, música e estilo, rejeitando-se a ideia de subcultura(17) e favorecendo-se, p/ ex., a ideia de comunidades transitórias, caracterizadas por fronteiras fluidas e pertenças flutuantes(3). As noções de 'tribo' ou 'neotribo' têm sido apresentadas como solução para a questão, precisamente por traduzirem, no entender de vários autores, de forma mais adequada as práticas de consumo e sociabilidades juvenis ${ }^{(21)}$. Na perspectiva de Maffesoli(16), p/ ex., o conceito de tribo não apresenta a rigidez das formas de associação com as quais 
estamos familiarizados; refere-se mais a um certo ambiente, um estado de espírito, expressando-se preferencialmente através de estilos de vida que favorecem a aparência e a 'forma'. Esta via tende a 'esvaziar' ideologicamente as práticas juvenis, mas, como adverte Simões (21), tanto existem subculturas juvenis claramente politizadas, como subculturas cuja dimensão ideológica é mais ténue ou praticamente imperceptível. De qualquer modo, existe sempre alguma elaboração ideológica, mesmo que ao nível das representações sociais, traduzindo uma determinada justificação das práticas. Entendemos, pois, e seguindo a linha de Simões(21), que a escolha conceptual entre (sub)culturas ou (neo)tribos não é o mais relevante, mas antes a sua adequação entre a definição conceptual e a realidade que se pretende abarcar. Neste estudo, a realidade em causa é uma prática dos tempos livres, parecendo-nos, por isso, que o conceito de subcultura faz sentido. De facto, esta dimensão da vida quotidiana dos jovens é fundamental para a compreensão das culturas juvenis, quer o usufruto desses tempos livres seja considerado como meio de ajustamento ao meio social envolvente, quer como factor de integração geracional(18). A opção por determinada prática neste 'tempo de não trabalho' é crucial para a compreensão da própria heterogeneidade que caracteriza a juventude. É, pois, com base nesta heterogeneidade cultural da juventude que Pais(18) nos fala numa pluralidade de culturas juvenis. Simões(21) acrescenta ainda a ideia de subculturas juvenis, no entanto salienta que se, por um lado, a noção de subcultura reforça a ideia de diversidade cultural, tornando patente a diferenciação interna da sociedade, por outro, levanta o problema da forma como se estabelece a relação entre as diferentes subculturas e a sociedade/cultura mais vasta da qual fazem parte. A utilização da categoria subcultura detém, portanto, uma relação implícita de que a diferença existe entre a subcultura e a cultura dominante. Neste sentido, esta assume a forma de um qualquer grupo que, no contexto da sociedade geral, apresenta interesses que variam dos apresentados pela cultura dominante. Esta é socialmente determinada através de negociações levadas a cabo, não por indivíduos, mas por subgrupos sociais, ou subculturas. Porém, a cultura dominante está sempre presente e, simultaneamente, ausente, desafian- do uma definição. É esta dificuldade que está no coração das discussões acerca da 'distinção' das culturas, logo, da adequação de subcultura. Existe, com efeito, uma diversidade de definições para o conceito de subcultura, que resulta da sua utilização nos mais variados contextos teóricos e empíricos.

Encontramos, ainda assim, algum acordo entre os vários autores de que as subculturas são grupos de pessoas que têm algo comum entre si (partilhando um problema, um interesse, uma prática) que as distingue de um modo significativo dos membros de outros grupos sociais ${ }^{23}$. É de salientar que, apesar dos valores e normas partilhados por uma subcultura diferirem dos da cultura dominante, não são forçosamente de oposição ou desligados dos da sociedade em geral, existindo em interacção, influenciando e sendo influenciados pelos valores dominantes(4). Um dos trabalhos mais proeminentes no estudo das subculturas é o de Hebdige ${ }^{(9)}$, que descreve a subcultura com formas expressivas e ritualizadas de grupos subordinados. Para o autor, uma subcultura é uma área em que grupos de pessoas desafiam os significados dominantes associados aos produtos culturais. O seu trabalho apresenta-se muito actual, particularmente pelos elementos que surgem a caracterizar cada subcultura, sendo estes, a ideologia, a resistência social, a construção da identidade, e a simbologia e a estética. É no conjunto destas características que encontramos um modelo prévio para a compreensão do parkour, sendo, por isso, relevante abordar cada um dos elementos separadamente.

\section{Ideologia}

Um dos denominadores comuns nas subculturas é a existência de um conjunto de princípios, objectivos, motivos ou influências que permitem o surgimento de uma ideologia específica, sendo a partir desta ideologia que os restantes aspectos se desenvolvem. Nos desportos alternativos, é frequente uma ideologia relacionada com noções de fuga ao quotidiano. A escalada, com duas vertentes - a tradicional e a desportiva -, é um exemplo desse tipo de visão.

Segundo Kiewa(14), é na primeira que os escaladores obtêm o afastamento que pretendem, procurando a sua identidade pelo afastamento da sociedade. Contrariamente à escalada desportiva, na tradicional não se procura progredir facilmente, mas sim da 
forma correcta e, consequentemente, mais disciplinada e que requer mais conhecimentos, afastando o público ocasional. Para além da fuga ao quotidiano, Kiewa(13), num outro estudo, verificou que a base ideológica da escalada assenta também na busca pelo controlo. Com efeito, estas actividades requerem decisões de vida ou morte em situações de perigo que quando ultrapassadas com sucesso, geram uma sensação de controlo que dá confiança ao escalador, sendo um dos grandes factores motivadores desta prática.

Outros desportos estão intimamente ligados a outras formas culturais, como p/ ex., a música, vista tanto como fonte criadora de subculturas, como resultado dos processos criativos que surgem no seu seio(26). O skate é ilustrativo desta relação, sendo mesmo considerado um estilo de vida. Este desporto, pressupõe o improviso, a construção de manobras consoante os obstáculos da rua, mas enquanto subcultura deve muito do seu carácter de improviso e independência à influência da música punk(11). Segundo Hebdige ${ }^{(9)}$, esta subcultura afirmava-se como portavoz de uma juventude negligenciada, que obtinha do punk uma forma tangível da sua alienação, carregando, com a convicção necessária, o intervencionismo político. Mais tarde, Hunter ${ }^{11}$ verifica que para além do punk, o skate é também influenciado pela subcultura hip hop que, apesar de ter uma sonoridade diferente, pode assumir objectivos semelhantes ao desafiar os valores hegemónicos na sua tentativa de conquista de espaço público, como forma de auto-representação(8).

A ideologia do skate sugere-nos que as cidades podem ser actuadas a partir dos seus micro-espaços, tanto quanto através de grandes projectos e planos urbanos(19). Os skaters mostram-nos, deste modo, que o urbano não é somente um produto, é, sobretudo, um modo de vida. Existem outros desportos alternativos urbanos, cuja ideologia não é tão clara, no entanto, é possível encontrar alguns paralelismos. Pedrazzini(28), p/ ex., apesar de não aprofundar as influências ideológicas nas subculturas, realça a relação com o risco, com as formas desportivas clássicas e com os novos repertórios de movimento corporal, o que permite, olhando para lá das diferenças técnicas, afirmar que os praticantes dos desportos alternativos urbanos têm um perfil sócio-cultural próxi- mo. Se a esta constatação aliarmos exemplos de troca de influências ideológicas entre desportos alternativos, como demonstra Humphreys ${ }^{(10)}$ num estudo em que é possível verificar relações ideológicas entre o skate e o snowboard, a semelhança no perfil sócio-cultural torna-se mais consolidada. Assim, apesar da escassez de estudos relativos às influências culturais específicas de cada um destes desportos, pode-se afirmar que a ideologia relativa à prática é semelhante e que as outras influências ideológicas podem surgir do contacto entre os vários desportos alternativos urbanos.

\section{Resistência social}

Esta é a forma através da qual os elementos de uma subcultura revelam as suas diferenças relativamente à cultura dominante, estando também, frequentemente, associada à ideologia. Esta atitude adquire grande importância, pois desafia o conjunto de valores ditados pela sociedade, sendo, por isso, um dos aspectos mais apresentados nos estudos realizados sobre subculturas. Nos estudos realizados junto de praticantes de desportos alternativos, a resistência assume, por vezes, a forma de renúncia à competição formal, como se observa num trabalho com uma comunidade de skaters $^{(2)}$. Neste, é apontada a criação de normas alternativas e relações que enfatizam o papel do participante, como forma de resistência na subcultura do skateboarding. Esta passa pelo papel activo do participante no controlo da sua actividade e pela organização de eventos de participação livre como oposição aos eventos da alta competição. No skateboarding apela-se à prática livre sem regras, treinadores ou árbitros, incentivando os skaters a criarem as suas próprias manobras e o seu próprio processo de treino. Este tipo de comportamentos opõese àqueles observados no skate de elite, enfatizando a resistência criada por estes grupos de skaters amadores aos valores dominantes. A subcultura skater estende, ainda, a sua acção de resistência social para além dos domínios da competição formal na forma atípica como ocupa o espaço público e se desloca pelo mesmo. Como refere Pais ${ }^{(19)}$, na recusa do pré estabelecido, o skater apropria o espaço às suas necessidades, criando uma existência alternativa que vive apenas enquanto existe um grupo de pessoas que a utilizam de uma forma diferente. Deste modo, 
"as performances dos jovens skaters desafiam as hierarquias espaciais estabelecidas pela arquitectura convencional das cidades; promovem uma espécie de comunidade "translocal'"(19).

A própria noção de risco, muitas vezes associada aos desportos alternativos, relaciona-se com fenómenos de resistência social, como se verifica no estudo de Kiewa(14), no qual escaladores de escalada tradicional optam por renunciar aos equipamentos que facilitam a actividade e minimizam o risco. Afastam, assim, uma sociedade que vive o risco de outra forma e acaba por procurar emoções fortes na escalada desportiva que, por usar vários equipamentos que minimizam o risco e o cansaço, é aceite pelo público geral, mas não é vista como sendo genuína pelos escaladores tradicionais.

A resistência social apresenta também um reverso da medalha, i.e., por vezes surge acompanhada de processos de recuperação e acomodação social, sem os quais, dificilmente, alguma subcultura seria aceite pela cultura dominante. Referindo-se à forma como a sociedade lida com as subculturas, Hebdige( ${ }^{(9)}$ afirma que o processo de recuperação assume duas formas: a conversão de símbolos subculturais em materiais de consumo em massa e a catalogação e redefinição de comportamento desviante pelos grupos dominantes. Sobre os processos de acomodação, o autor realça o facto de ser difícil manter uma absoluta distinção entre exploração comercial e criatividade/originalidade, mesmo sendo estas categorias marcadamente opostas no sistema de valores de muitas subculturas. Assim, os estilos culturais juvenis podem começar por lançar desafios simbólicos, mas têm que inevitavelmente estabelecer novos conjuntos de normas, através da criação de comodidades, novas indústrias, ou recuperando antigas. As subculturas quebram as regras através do reposicionamento, da recontextualização do consumo, subvertem o uso convencional dos objectos e investigam novas funções. Demonstram, assim, uma nova forma de encarar as práticas quotidianas ${ }^{(9)}$.

\section{Construção da Identidade}

Os estudos em que existe uma metodologia centrada na observação participante incidem, frequentemente, na construção da identidade no seio de um grupo e nas normas pelas quais se rege esse grupo. O pro- cesso de construção da identidade é criado através de uma rede complexa de símbolos, conhecimentos e atitudes que vão no sentido de consolidar a posição de um indivíduo num determinado contexto. Esta consolidação dá-se muitas vezes através da aceitação de um conjunto de normas e/ou rituais de iniciação que, sendo respeitados, permitem ao indivíduo obter o estatuto de membro. Este é um processo inescapável ao sujeito que pretende ser aceite pelos membros de uma subcultura. Tal como evidencia Hunter(11), a identidade social refere-se à forma pela qual indivíduos e grupos são distinguidos nas suas relações sociais com outros indivíduos e grupos. Assim sendo, a identidade social é tão necessária ao desenvolvimento de relações sociais, como o inverso, i.e., as relações sociais e a identidade social são pré-requisitos para a existência de ambas, estando o processo de construção de uma, intimamente ligado ao da outra. Só assim se explica a necessidade da construção de uma identidade sólida e segura para que um estatuto estável possa ser atingido dentro do grupo. O autor realça ainda que a identidade social se obtém faseada e diversamente, como p/ ex., através do estilo, i.e., da distinção da sociedade em geral, pelo uso de vestuário específico. Deste modo, é permitido aos iniciantes, mesmo sem domínio técnico, serem reconhecidos como skaters. Mas à medida que o tempo passa, e o sujeito se torna mais competente tecnicamente, a importância dada aos símbolos exteriores diminui, já que a competência na actividade ligada à subcultura se assume como o símbolo mais poderoso de definição de uma identidade social. A importância da competência é também confirmada na subcultura surfista, em que saber surfar é o principal cartão de identidade(6). Todos os outros meios, como o vestuário, o conhecimento dos meios de comunicação especializados, ou a linguagem perdem importância, por não serem constantes de região para região.

Frequentemente é criado um código de conduta mais ou menos explícito que dita a construção da identidade no seio de uma subcultura. Como evidencia Kiewa ${ }^{(14)}$, a escalada tradicional representa a antítese da acção racional, havendo comportamentos típicos no escalador genuíno, e cuja ausência pode comprometer o processo de integração. O escalador real é aquele que escala por gosto e não por exibicionismo 
e glória; deve procurar ser reservado e não espalhafatoso. É incentivada a igualdade entre escaladores, já que a humildade é uma qualidade valorizada, sendo esta atitude demonstrada através da pouca relevância dada a níveis ou graduações. Por fim, o escalador deve estar disposto a aprender correctamente as técnicas e não enveredar pelos caminhos facilitados da escalada desportiva.

\section{Simbologia e Estética}

É importante analisar a importância que o poder representativo dos símbolos tem no seio de uma subcultura, pois o modo como os membros utilizam o vestuário, a linguagem, e outras formas simbólicas, faz com que sejam facilmente identificados como pertencentes a um determinado grupo. Volosinov(25) afirma que o domínio da ideologia coincide com o dos sinais: sempre que um sinal está presente, a ideologia também está; tudo o que é ideológico possui um valor semiótico. De facto, o estilo na subcultura está impregnado de significado. As suas transformações vão contra o que é natural, interrompendo o processo de normalização, e os gestos e movimentos, direccionados para um discurso que ofende a maioria silenciosa, desafiam os princípios de unidade e coesão. A utilização de um conjunto estabelecido de vestuário, danças, música, etc., serve, então, para demonstrar a diferença e comunicá-la à sociedade. A diferença destes conjuntos simbólicos reside no facto de, contrariamente aos convencionais, se centrarem no indivíduo que as usa atraindo para si a atenção. Juntos, objecto e significado, constituem o símbolo e, em qualquer subcultura, estes símbolos são construídos repetidamente, até se tornarem formas características do seu discurso(9).

O vestuário, como forma exterior mais imediata de representação de uma subcultura, é assinalado num trabalho com skaters, no qual se descreve como a moda e a identidade social se interrelacionam nesta subcultura(11). Os membros são descritos como usando roupa muito relaxada e informal, sob a forma de calças largas, $t$-shirts e sweat-shirts com carapuço. Talvez mais importante que o vestuário, serão os símbolos representados no mesmo. Entre os mais frequentes encontram-se as bandas ou cantores favoritos, denunciando a importância da música, ou o logótipo da marca favorita (normalmente marcas especializadas ou criadas pelos próprios skaters), demonstrando, por um lado, um conhecimento especializado sobre o desporto e, por outro, a rendição aos valores consumistas da sociedade geral. O vestuário traduz, assim, a união entre indivíduos do mesmo grupo, significando, simultaneamente, a exclusão em relação a todos os outros grupos. Também nesta subcultura, o equipamento é parte da indumentária e representa um símbolo pelo qual os skaters podem ser reconhecidos. De acordo com Steyn ${ }^{(22)}$, a tábua do skate é um elemento simbolicamente importante por se tornar numa micro-representação do skater. Ao renunciar o desenho original e apostar na personalizaçãoi, o skaters transmite informações importantes que permitem, por um lado, o afastamento de determinados grupos e, por outro, a aproximação de grupos com afinidades relativas ao que representam os autocolantes.

Estes elementos simbólicos partilham o mesmo espaço representativo, necessitando de ser coerentes dentro do espaço onde se inserem. Para descrever a coordenação simbólica entre valores e estilos de vida de um grupo, a sua experiência subjectiva e a forma musical que usa para expressar e reforçar os seus interesses centrais, Paul Willis(28) introduziu a noção de Homologia. Segundo o autor, a estrutura interna de uma subcultura é caracterizada por uma extrema ordenação e organização: cada parte está organicamente relacionada com as outras e é através desta relação que o membro da subcultura dá sentido ao mundo. Assim, os símbolos, através da homologia, representam os mesmos pressupostos. Cada símbolo, quer seja vestuário, linguagem, arte gráfica, música, etc., encerra em si a mesma ideologia, a mesma estética que caracterizam uma determinada subcultura.

\section{A apropriação do espaço urbano nos desportos alternativos}

A redescoberta do espaço urbano constitui um processo que é capaz de desafiar a ordem hegemónica, através da criação de ocasiões de contestação e afirmação, superando os seus limites e constrangimentos ${ }^{(15)}$. Estes mecanismos de apropriação do espaço geram estilos e usos, combinando-se em novas formas de viver a cidade. A cada nova forma que surge, a identidade colectiva da cidade vai-se diluindo até que cada grupo, cada subcultura, viva o meio de 
forma particular, representando-o e experimentandoo de maneira distinta. Este é o habitat das várias subculturas, encontrando-se algures neste conjunto, os desportos alternativos urbanos e a sua peculiar forma de afirmação no meio urbano. Na realidade, muitos dos recentes desportos alternativos são praticados nas cidades, afectando o espaço público. É neste contexto que o skate, o inline skating ou o freestyle bmx (e agora o parkour), se tornam, a cada dia que passa, mais frequentes na paisagem urbana contemporânea.

O modo como os seus praticantes vivem a cidade é diferente dos restantes habitantes e visitantes. As suas atitudes e acrobacias chamam a atenção e constituem-se como um novo entretenimento. Os desportos que têm lugar nas cidades não seguem uma organização rígida, guiando-se antes pelo ritmo de vida da cidade. Como exemplo, Camy, Adamkiewics e Chantelat ${ }^{(7)}$ descrevem como numa rua de Lyon o espaço é ocupado de forma fluida por um grupo de skaters, que adapta o seu espaço consoante o fluxo de pessoas que a cruzam ao longo do dia. Este uso alternativo do espaço urbano provoca, no entanto, alguns conflitos, nomeadamente, em áreas comerciais movimentadas, onde existe o risco de choque com outras pessoas e veículos. Isto leva os praticantes a procurarem outros momentos ou outros locais para a sua prática. Também Karsten e Pel(12) evidenciam a apropriação do espaço urbano, descrevendo como os skaters acomodam o espaço que ocupam às suas necessidades: todos os objectos são potencialmente um obstáculo a ultrapassar; mais, é nestes locais que constroem obstáculos, reparam equipamentos, convivem e trocam experiências.

Uma outra característica dos praticantes de desportos urbanos é a sua mobilidade. Alguns praticantes movem-se constantemente de local para local, como os street skaters; outros procuram um local específico com as condições perfeitas, com o objectivo de praticarem o downhill ou os grinds (manobras do skate). Não é, portanto, de admirar que locais com condições temporariamente alteradas causando incómodos para a restante população, sejam espaços óptimos para a prática destes desportos. De facto, para além das formas de representação mais imediatas, surgem outras, mais subtis, concernentes aos novos discursos resultantes de uma utilização alternativa dos espaços. Como refere Pais(19), o local que os skaters ocupam torna-se um espaço de expressão simbólica, cuja escolha se prende com necessidades expressivas, nas quais o ver e ser visto assume um papel importante. "O corpo do skater dialoga com a arquitectura do espaço por onde desliza, como se nesse 'corpo a corpo' se produzisse uma nova discursividade urbana" (19).

Os habitantes das cidades começam, então, a reinterpretar o espaço urbano e as actividades que nele se desenvolvem. Passeios, ruas, parques, espaços livres entre edifícios, são usados como local de prática de desportos de forma informal. Por conseguinte, o carácter funcional da relação entre os praticantes de desportos alternativos urbanos e a construção do ambiente envolvente não pode ser ignorado. $\mathrm{O}$ conhecimento que estes sujeitos têm da 'rua' tornaos conhecedores das questões urbanas sem que alguma vez tenham lido algum livro sobre urbanismo. Os praticantes destes desportos são constantemente desafiados a pensar a cidade, os seus quarteirões e os seus habitantes, fazendo-o crítica e activamente. Na sua deambulação pela cidade, transportam consigo a faceta humana da urbe, fazendo ressurgir a cidade.

\section{METODOLOGIA}

Este trabalho baseia-se numa pesquisa assente numa observação participante ${ }^{5}$, a partir da qual o investigador procura participar no quotidiano, partilhando experiências desse mesmo quotidiano dos actores sociais. Será de dentro, então, que o investigador obterá elementos para, então, interpretar os significados e experiências dos actores sociais. De facto, só a experiência pessoal permite entender os processos inconscientes de tomada de decisão, por exemplo, quanto à forma de encarar o risco e abordar cada obstáculo.

O grupo seleccionado constituiu-se por jovens, entre os 15 e os 17 anos, praticantes de parkour, não havendo um número fixo de elementos. Como referência existiu apenas o nome, Legião 12 (L12), que diz respeito ao número de elementos aquando do 'baptismo' do grupo. Esta foi uma observação activa(5), por oposição a um tipo de observação mais passiva na qual os dados são registados durante a observação. Logo, o comportamento durante os trei- 
nos foi semelhante ao dos restantes elementos, permitindo, não só a observação do seu comportamento, mas também experimentar sensações que não são facilmente descritíveis e, certamente, impossíveis de perceber apenas pela observação. Marcámos presença nos dias em que se combinavam treinos, e que foram mais frequentes durante o Verão. Em cada registo de observação procurou-se manter uma descrição detalhada dos novos locais por onde o treino foi passando. Durante a recolha foram obtidos dois tipos de dados, os que são do tipo da descrição narrativa, resultantes das notas de campo, e aqueles que pertencem ao tipo da compreensão, fazendo apelo ao uso da subjectividade ${ }^{(18)}$. Inicialmente foram descritos os elementos concretos da situação e anotadas as conversas dos indivíduos observados. Assim, os relatos iniciais têm uma componente mais descritiva relativamente aos vários locais onde decorreram os treinos, às formas como os vários elementos se relacionam entre si e em relação à maneira como representam simbolicamente o facto de serem traceurs. Com estas informações de base, os relatos posteriores basearam-se na manutenção de um diário de bordo, que se assume como um conjunto de registos de observação, no qual foi anotado o percurso ao longo dos vários treinos. Neste, foi relatada a experiência na primeira pessoa, a de ser também um traceur, as reflexões pessoais, as percepções, as expectativas e receios, as relações com o grupo, e todos os elementos novos que viessem enriquecer a informação recolhida, desde novos locais, às novas atitudes por parte dos elementos, à receptividade face aos novos elementos que foram aparecendo, às mudanças de visual. Para além das relações estabelecidas com o grupo no papel de traceur, foi estabelecida uma relação privilegiada com Xavi (um dos elementos da L12), visto que desde o início se tornou um informante privilegiado, fornecendo relevantes informações em relação aos vários membros do grupo e em relação ao parkour, ajudando a confirmar a validade dos dados que iam sendo recolhidos.

Durante o processo de observação participante, algumas das categorias foram facilmente observadas, mas outras permaneceram algo escondidas por estarem implícitas na forma como os vários elementos se relacionavam entre si e com o meio envolvente. Foi, por isso, necessário recorrer à realização de entrevistas semi-estruturadas(20), nas quais se utilizam uma série de temas e tópicos a discutir no decurso da conversa.

De acordo com o quadro teórico previamente estabelecido, preparou-se o guião de entrevista, isto é, que testado com praticantes de parkour de outros grupos. Utilizámos a entrevista para tentar atingir o que não é visto, ou seja, o que não é percepcionado, i.e., "a função da entrevista é chegar ao desconhecido, ao 'não visto' ou, melhor dizendo, somente ao 'entrevisto'. O entrevisto é justamente o 'visto imperfeitamente', o 'mal visado', o apenas 'previsto' ou pressentido" (18). Constituiu-se então como objectivo da entrevista conseguir ir um pouco mais além das palavras ouvidas. A transcrição das entrevistas e o diário de campo, com os respectivos registos de observação, constituem o nosso corpus de estudo. Adicionalmente, para melhor compreender o parkour serviram ainda como elementos para a análise, os sítios nacionais e internacionais dos principais grupos de parkour, e vários artigos publicados em revistas e jornais. $\mathrm{O}$ corpus de estudo foi, então, sujeito à análise de conteúdo que segundo Bardin(1) é um "conjunto de técnicas de análise das comunicações, que utiliza procedimentos sistemáticos e objectivos de descrição do conteúdo das mensagens". Este processo compreende algumas operações mínimas: a delimitação e dos objectivos e definição de um quadro de referência teórico; constituição de um corpus; definição de categorias; definição de unidades de análise(24). Para finalizar, a informação resultante desta análise, passou por um processo de exploração e descoberta que foi possível através de um esforço interpretativo, no sentido de tornar visível o conteúdo resultante de todo este processo. Para esta análise partimos do modelo teórico anteriormente exposto, com as categorias ideologia, resistência social, construção da identidade e simbologia e estética. Da leitura e análise mais aprofundada de todo o corpus de estudo, emergiram duas novas categorias para discussão, nomeadamente: independência face ao espaço global e a relação com o espaço de prática. As unidades de análise utilizadas foram as de contexto(24) que, por serem mais alargadas, permitem uma codificação e inventariação contextualizada dos textos obtidos.

O resultado da nossa pesquisa será seguidamente 
desenvolvido, partindo de uma caracterização geral do parkour, para então passarmos ao modo como as categorias de uma subcultura se revelam nos sentidos das práticas da L12.

\section{O PARKOUR}

Fazer das barreiras um desafio e inventar formas fluidas e orgânicas de ultrapassá-las. Foi com este pensamento que David Belle e Sébastien Foucan começaram a desenvolver um método e uma filosofia que inspiraram milhares de jovens por todo o mundo. Definido por Belle como a arte de ultrapassar obstáculos, o parkour constitui-se como uma forma de deslocamento e uma nova maneira de interagir com o envolvimento urbano. Segundo a descrição presente no sítio parkour.net, onde as pessoas vêem obstáculos, os traceurs vêem oportunidades que envolvem saltos, movimentos diferentes, originais. A ideia é utilizar os obstáculos e progredir pelo meio urbano de um modo natural e fluído. O principal objectivo é conseguir naturalidade e fluidez no deslocamento, porém, é possível realizar movimentos mais redundantes para acrescentar beleza ao movimento. É na forma de ultrapassar os obstáculos que se distingue o parkour e o free running; embora ambos procurem a libertação do corpo num contexto, preferencialmente urbano, divergem num aspecto energético: a eficiência do deslocamento. Enquanto o parkour defende a simplicidade, a fluidez e a velocidade das progressões, o free running associa-se a uma elaboração mais complexa dos movimentos que permitem ultrapassar os obstáculos que vão surgindo. Encontramos praticantes desta modalidade um pouco por todo o mundo, sendo os meios de comunicação os principais responsáveis por este facto. $\mathrm{O}$ fenómeno global iniciou-se com o documentário Jump London, que ao ser transmitido um pouco por todo o mundo levou a actividade para lá de França e Inglaterra. Facilmente se encontram páginas de grupos de parkour em várias línguas e provenientes de vários países, mas existem referências que qualquer pessoa com aspirações a praticante deverá consultar: as páginas pessoais de David Belle e de Sébastien Foucan e a página do maior grupo de parkour a nível internacional, os Urban Free Flow. Também o cinema tem demonstrado interesse nesta actividade, como é o caso do último filme de James Bond, ou mesmo do filme que lançou o parkour para o estrelato, Yamakasi. A sua vertente mais artística pode ser observada em produções como o videoclip da música Jump (2005) de Madonna. No campo virtual, a sua presença também é notória; para além dos videojogos realizados, especificamente sobre parkour, existem muitos outros onde facilmente a sua influência é identificada. Também em Portugal é possível verificar o mesmo tipo de burburinho em volta do parkour por parte dos media. Além da divulgação internacional que chega ao país, existem vários artigos escritos sobre a actividade em algumas das revistas mais lidas do país, como é o caso da Notícias Magazine ii, da Sport Life iii ou da revista de cultura urbana Umbigo. Na internet facilmente se encontram os sítiosiv de grupos espalhados pelo país, onde, para além das informações básicas acerca do parkour, se divulgam os próprios vídeos, assim como locais e horários de treinos e encontros locais e nacionais.

Um outro factor que terá contribuído para a divulgação desta actividade foi o aparecimento de praticantes desta actividade em séries juvenis portuguesas de grande sucesso, expondo o parkour a um número ainda maior de pessoas. No entanto, mesmo com a cobertura mediática existente, esta não é (ainda) uma actividade massificada, como se verifica através do número de inscritos no fórum do sítio nacional de parkour. Devido ao tipo de meios de comunicação social onde é divulgado, o parkour é conhecido essencialmente pela população jovem.

\section{O PARKOUR ENQUANTO SUBCULTURA}

Tomando como referência os elementos estruturadores de uma subcultura desenvolvidos na primeira parte do trabalho, e acrescentando os que advieram do trabalho empírico, procuramos, agora, uma compreensão do parkour vivido na L12 enquanto subcultura urbana.

Relativamente à ideologia, o parkour apresenta uma relação com as artes marciais que o diferencia de outros desportos. É uma influência observada em ambos os sentidos, i.e., não só o parkour teve influência no gosto pelas artes marciais, como alguns elementos do grupo já tinham praticado artes marciais antes de conhecerem o parkour. Através da observação participante foi possível constatar que esta influência se manifesta na atitude disciplinada 
com que treinam e encaram a sua actividade, apesar de ser um desporto de lazer, e sem competição formal. É de esperar que, à medida que este desporto se for tornando mais popular, siga o rumo dos outros desportos alternativos, permanecendo pequenos grupos como o estudado, os representantes da visão inicial do parkour.

Em subculturas como o snowboard ou o skate, é notória a influência, sob o ponto de vista ideológico, da subcultura punk. Em relação ao parkour, porém, e devido à curta história, não podemos estabelecer uma relação clara entre um estilo musical e a ideologia desta subcultura. Não obstante, todos os elementos entrevistados referiram a importância da música na obtenção de estados emocionais mais propícios ao parkour. Nas palavras de Xavi: "Gosto de tudo, mas especialmente de músicas que façam subir a adrenalina. Rock, punk, há quem use hip hop, mas isso é para movimentos mais calmos, mais fluidos. De forma geral, é rock ou até electrónica...coisas pesadas". A música desempenha, pois, um papel importante, mas não a um nível ideológico. Tanto no grupo observado como em fóruns nacionais e internacionaisv, a maioria das referências é dirigida a estilos musicais ou grupos com ritmos rápidos, eléctricos, e estimulantes, que ajudam a preparar a mente para a acção, como se confirma no discurso de John relativamente à relação entre a música e o parkour: "na parte da adrenalina. Até tens o exemplo de vários vídeos que se faz parkour. Têm sempre músicas de adrenalina e eu gosto desse estilo". Fica, então, presente a ideia de que se dá preferência a ritmos mais enérgicos, podendo ser esta uma pista para o desenvolvimento de uma futura relação com um estilo musical com estas características. Ainda relativamente à ideologia, tem havido, desde o início, uma renúncia à competição formal, que se verificou, igualmente, no grupo observado, e que foi confirmada pelos elementos do grupo. A situação descrita a seguir ilustra isso mesmo: Xavi descobriu uma gap e desafiou Jump a ultrapassá-la, que aceitou o desafio e com aparente facilidade ultrapassou o obstáculo proposto. Em tom de brincadeira, Xavi propôs uma competição para ver quem conseguia ultrapassar mais rapidamente esse obstáculo. À competição, Jump respondeu com uma pequena repreensão: "Aqui não há competições, isto é parkour!"
Apesar de ter sido uma brincadeira, serviu para confirmar a relação que os elementos do grupo têm com a competição, negando-a até em momentos onde não assume carácter formal. No entanto, mesmo não existindo um desafio directo nem competição organizada, esta existe de forma latente. Sempre que um novo obstáculo é ultrapassado ou uma nova manobra é dominada, todos os elementos tentam fazer o mesmo. Não existem pressões explícitas, mas o sentimento é bem real e confirmado nas entrevistas, sendo esta competição latente a base da evolução do grupo. "É sempre bom competir, ajuda-nos a desenvolver". Quem o diz é Climb.

A resistência social também está presente no grupo observado, expressando-se de diversas formas. A mais notória revela-se no modo como se tenta conquistar um espaço de expressão que, apesar de não ter um cariz de confronto directo com os valores vigentes, acaba por, inevitavelmente, chocar com as restantes pessoas que vivem o espaço público. Foi possível encontrar esta categoria em várias situações. Sempre que o grupo decidia percorrer algum local com características urbanas, tinha comportamentos que nos permitem confirmar um tipo de resistência social próprio. Como foi possível presenciar enquanto observador participante, "a excitação partilhada pelo grupo nestas incursões mais urbanas evidenciava algo mais". Demonstrava, juntamente com os discursos entusiasmados, relativos aos confrontos que tinham tido anteriormente naqueles locais, que a prática num lugar calmo é muito boa, mas a sensação de desafiar as regras é algo que aumenta a motivação. Uma das situações mais esclarecedoras acerca da forma como a resistência social se dá, aconteceu durante a Jam, como demonstra o seguinte excerto do diário de campo: "Não foram precisos mais de 10 min para que um dos porteiros dos apartamentos nos viesse avisar que não podíamos estar ali a treinar. A reacção do grupo não foi negativa, mas decidimos não abandonar o local para testar a determinação do porteiro. Na realidade, não havendo nenhum sinal proibindo qualquer actividade naquele local, sentíamos o direito de o explorar como bem entendíamos, até porque não estávamos a causar danos materiais. No entanto, os danos causados na sensibilidade do porteiro foram suficientes para que voltasse ao lugar, e agora num tom mais ameaçador nos 
mandasse embora dali. Enquanto procurávamos um novo local, cada grupo ia contando os inúmeros confrontos com os vários porteiros avessos ao parkour, demonstrando que aquela era uma situação à qual estavam acostumados. Acabámos por rodear o prédio e deparámo-nos com um espaço igualmente convidativo e, aparentemente, escondido o suficiente para que não fossemos incomodados. Este local não estava à face da rua e tinha, do outro lado, edifícios abandonados, por isso não havia razão para se pensar que estaríamos a incomodar alguém. Realmente, conseguimos treinar durante mais algum tempo, mas infelizmente, um outro porteiro veio dizer-nos que não podíamos estar ali. O grupo percebeu que naquela zona não iria poder treinar e decidimos procurar novamente um local. Apesar de acatarmos as ordens sem grande resistência acabámos por demonstrá-la no caminho de volta. Quase espontaneamente, sem que ninguém dissesse nada, começámos em corrida lenta a utilizar tudo o que podíamos para treinar. Tínhamos a consciência que não podíamos estar num local durante muito tempo, mas em constante movimento, não havia porteiro que nos apanhasse e na altura que desse pela nossa presença já estaríamos a sair da sua "jurisdição'”.

Através da observação participante, foi possível viver na primeira pessoa processos de construção de identidade e de dinâmica de grupo, sendo possível afirmar que não são substancialmente diferentes dos verificados noutros estudos. Quando demos por terminado o trabalho de campo, foi possível olhar para trás e identificar os processos que tornaram a integração um sucesso. Em primeiro lugar, a abertura demonstrada por Xavi permitiu entender a sua importância no seio do grupo e a importância de entrar no grupo através de algum membro. Um outro aspecto, que mais tarde foi confirmado através das entrevistas realizadas, foi o empenhamento demonstrado e a partilha da paixão pela actividade, tal como se pode confirmar pelo discurso de Jump: "Pah(sic)...alguém diz hoje vamos treinar e o pessoal vai todo, ou então não vai porque não pode mesmo. Há muita dedicação... é importante que alguém se dedique para conseguir estar bem no grupo. Se alguém andar aqui contrariado nota-se logo e, oh pah (sic), o grupo começa a excluir". De facto, foi possível verificar que estes dois factores são, talvez, os mais importantes no processo de aceitação. Como mais tarde foi possível observar, a entrada de elementos com uma visão diferente acerca do parkour veio abalar a estabilidade do grupo, levando a uma fase em que os membros mais antigos estiveram, claramente, menos motivados para treinar. O processo de iniciação começou, então, como consta no diário de campo "sem treinador, sem líder, sem alguém que dissesse como, tentando ultrapassar os obstáculos perseguindo o grupo. Esta é, realmente a prova que quem inicia esta actividade tem que passar. Todos os outros são perfeitamente autónomos. Ninguém pergunta como ultrapassar determinado obstáculo. Se não se consegue de uma forma consegue-se doutra". Desta maneira, um elemento iniciante vai vencendo, obstáculo a obstáculo, as dificuldades iniciais até conseguir acompanhar o grupo nos seus percursos. Obviamente que o processo não é exclusivamente individual. Sempre que parámos, aproveitámos para trocar impressões acerca das experiências e dificuldades que fomos tendo. Como se pode ver pela seguinte passagem: "É aqui que o grupo assume a sua função. Os intervalos servem para descansar e conviver desenvolvendo os laços que os desafios que se encontram desenvolvem". Nos primeiros treinos as paragens serviram também para me perguntarem como é que me estava a sentir e se assegurarem que a minha experiência estava a ser positiva. Em acção, o grupo assume características muito específicas. É muito valorizada a capacidade de todo o grupo ser capaz de realizar algo, de forma a que se crie um movimento ininterrupto de passagem sobre um determinado obstáculo. Assim, como se constatou no trabalho de campo: "mais do que a construção de "heróis" dentro do grupo, tentase construir um grupo capaz de ultrapassar, em conjunto, os obstáculos que surgem". Apesar de ser valorizado o grupo e de não existirem tentativas explícitas no sentido da afirmação de uma posição superior, foram observadas algumas situações em que um maior domínio da prática levou a uma inevitável admiração por parte dos restantes e, consequentemente, à consolidação da posição dos elementos dentro do grupo. Este tipo de situações verificouse várias vezes e confirmou que os mais dedicados eram também os que, normalmente, tinham um maior domínio técnico e dos conhecimentos acerca 
do parkour, concedendo-lhes uma posição destacada no grupo. Estes processos estão, pois, mais encaminhados para uma dinâmica intimamente relacionada com a unificação do grupo, havendo, no entanto, lugar para a construção de discursos de maior ou menor autenticidade, dependentes em grande parte do nível de empenho e competência. Estes discursos manifestam-se essencialmente no contacto directo entre os vários traceurs, mas a Internet também fornece um importante meio de divulgação. À semelhança do que foi verificado por Williams ${ }^{26}$, este é um meio que permite a afirmação individual enquanto membro de uma subcultura. No parkour esta afirmação toma a forma de vídeos divulgados pelos grupos, onde se observam os vários elementos em acção.

Tal como noutras subculturas, existe no parkour uma simbologia e estética própria, que se nota particularmente na forma como o traceur se relaciona com o seu corpo em movimento e no modo como ocupa o espaço de prática. Este aspecto é mais relevante no parkour que noutros desportos alternativos, nos quais a estética está mais relacionada com o próprio vestuário; um reflexo da influência de outras formas culturais, como o punk. No parkour, o principal fio condutor é a funcionalidade, sendo possível encontrar semelhanças com o vestuário das artes marciais através dos símbolos adoptados por grupos internacionais como os Urban Free Flow. Quanto à forma de expressão no espaço, a observação participante permitiu constatar que o grupo "formava frequentemente uma fila, seguindo um trilho por entre os obstáculos que era traçado pelo elemento da frente. Em determinados momentos existiu a preocupação em fazer as coisas de acordo com certos padrões estéticos relacionados com o parkour". A fila em movimento constante representa a fluidez que, em termos visuais, causa sensação entre os praticantes, tanto quando observam como quando são os próprios em acção. Já em relação ao vestuário, os elementos do grupo caracterizaram um traceur sem divergências, o que demonstra já uma estética consensual. Nas palavras de Xavi: "Há um padrão. São sempre roupas que te permitem mover, dão-te sensação de conforto e isso tudo e que no fundo te identificam como traceur pelo vestuário que usas. $\mathrm{P} /$ ex., na nossa primeira jam não conhecíamos ninguém, mas olhámos à volta e identificámos quem estava no sítio e era traceur". Adicionalmente, ao longo do trabalho de campo, foi observada uma evolução do grupo no sentido de se apresentar de acordo com o que os próprios definiram como o visual típico de um traceur. Um exemplo ilustrativo desse cuidado foi a criação de um logótipo da L12 que os elementos começaram a usar nas $t$-shirts.

Passando a uma categoria mais observada nos desportos alternativos, a L12 demonstrou várias atitudes de afastamento em relação à forma como o parkour parece estar a evoluir a nível global, como se pode verificar no discurso de Xavi: "Nunca tivemos um grande contacto com outras equipas ou com outro pessoal que fizesse, portanto, parece que desenvolvemos uma outra vertente do parkour em si". E em relação à possibilidade de uma competição, Xavi afirma: "A mim não me aquece nem arrefece, quem quiser competir compete, e quem não quiser mantém-se purista. Tanto mais que, ao início, quando havia só o parkour, apareceu também o free run por causa da vertente mais estética". Parece, pois, estar imune aos crescentes indícios de uma competição formal. E, acima de tudo, desenvolveu a sua própria vertente, sem necessidade de definir se fazem parkour ou free runnig. No centro das preocupações dos elementos deste grupo está a criação de formas alternativas de normas e relações que enfatizem o papel de cada um, sendo que o mais importante é viver o espaço envolvente da forma que melhor lhes parece no momento, seja através de uma vertente ou outra. Por fim, no que diz respeito à forma como vivem o espaço de prática, verificámos que existem dois tipos de relação com o espaço. Em locais mais extensos, "utilizam-se corrimões, muros, escadas e restantes obstáculos, numa exploração exaustiva e criativa dos espaços". Já em locais menos amplos, a tendência é para o aperfeiçoamento de técnicas, como demonstra o seguinte excerto do diário de campo: "Já a rocha em si, tem todas as faces diferentes permitindo realizar vários elementos com vários níveis de dificuldade, o que permite um ataque contínuo por parte de todos os elementos. A dinâmica criada, na tentativa de superar os elementos que aparecem no percurso, é como uma micro representação do que se passa nos espaços amplos, onde continuamente desafiamos aquele obstáculo até que seja tão impeditivo à locomoção como uma pequena pedra". 
Os treinos decorrem em espaços, preferencialmente recatados, onde é possível treinar elementos mais difíceis sem a pressão exercida por observadores externos, mas esta nova forma de viver o meio urbano expressa-se na urbe onde os obstáculos abundam e a mensagem pode ser transmitida.

\section{CONCLUSÃO}

Ao analisarmos o parkour no contexto das subculturas urbanas foi-nos possível, através de um trabalho interpretativo sobre o diário de campo e as entrevistas realizadas, identificar as características subculturais que se manifestam neste desporto. Por este motivo, pensamos existirem dados suficientes para considerar o parkour como uma subcultura, apesar da sua história recente. Existem já elementos observáveis em todas as categorias que identificámos. $\mathrm{O}$ parkour pertence, assim, à imensidão do espaço urbano, seja por entre os densos espaços urbanizados ou nos seus recatados parques. Este desporto aparece como uma subcultura, que toma a própria dinâmica por si criada como forma cultural, e tem como base ideológica um sentimento de harmonia e união com o espaço de prática que faz com que a sua utilização não se paute pela ruptura com os valores estabelecidos, mas através do seu ganho progressivo. É na conjugação de todos estes aspectos que ganha vida uma nova subcultura. $\mathrm{O}$ corpo torna-se instrumento de liberdade e um meio de redefinir a paisagem urbana. O que antes eram barreiras ou obstáculos tornam-se continuações naturais de ruas ou passeios. Este desporto cria, assim, um mundo paralelo de liberdade de movimento (e expressão) dentro da amálgama de obstáculos e inibições das cidades actuais.

Tendo em conta a curta história deste fenómeno, ficaram várias questões por responder. Não podemos, p/ ex., afirmar que existe uma relação vincada com algum género musical, mas os dados recolhidos apontam mais para o desenvolvimento dessa relação que para a sua inexistência. Como não existe qualquer tipo de competição formal ficou por saber, também, de que forma reagiriam os elementos do grupo observado a tal facto. Face ao exemplo dos outros desportos alternativos, a única incógnita será quando é se inverterá a situação, i.e., quando é que se tornará a visão mais purista do parkour, a excepção à regra.
NOTAS

${ }^{i}$ Após comprarem as suas tábuas, estes praticantes, cobriam os logótipos das empresas fabricantes com autocolantes por eles criados, de forma a personalizar o seu skate e torná-lo menos "comercial".

ii Suplemento do Jornal de Notícias e do Diário de Notícias $\mathrm{N}^{\circ}$ 737 de 09/07/2006

iii De 2006

ivPor exemplo, www.parkour.pr; www.parkourptcentro.net;

FreeRunning.pt.vu; www.madeiraparkour.pt.vu/;

http://vkpt.com.sapo.pt/, etc.

v Por exemplo, www.parkour.pt ou www.urbanfreeflow.com.

\section{CORRESPONDÊNCIA}

\section{Ana Luísa Pereira}

Faculdade de Ciências do

Desporto e de Educação Física

Universidade do Porto, Portugal

R. Dr. Plácido Costa, 91

E-mail: analp@fade.up.pt 


\section{REFERÊNCIAS BIBLIOGRÁFICAS}

1. Bardin L (1977). Análise de conteúdo. Edições 70, Lisboa

2. Beal B (1995). Disqualifying the Official - an Exploration of Social Resistance through the Subculture of Skateboarding. Sociol Sport J 12: 252-267

3. Bennett A (1999). Subcultures or neo-tribes? Rethinking the relationship between youth, style and musical taste. Sociology 33: 599-617

4. Brake M (1985). Comparativeyouth culture. Routledge \& Kegan Paul, London

5. Burgess R (1997). A pesquisa no terreno. Uma introdução. Celta Editora, Oeiras

6. Butts L (2001). Good the last drop. Understanding surfers' motivations. SOSOL Sociology of Sport Online 4: [http://physed.otago.ac.nz/sosol/v4il/v4ilbutt.htm]

7. Camy J, Adamkiewics E, Chantelat P (1993). Sporting Uses of the City: Urban Anthropology Applied to the Sports Practices in the Agglomeration of Lyon. International Review for the Sociology of Sport 28: 175-185

8. Haupt A (1996). Notions of rupture (or noise) in subculture. In: Inter Action 4 Proceedings of the Fourth Postgraduate Conference, Bellville. UWC Press, pp 64-67

9. Hebdige D (1979). Subcultures: The meaning of style. Methuen, London

10. Humphreys D (1997). 'Shredheads go mainstream'? Snowboarding and alternative youth. Int Rev for Soc of Sport 32: $147-160$

11. Hunter J (2002). Flying-through-the-air Magic's: skateboarders, fashion and social. Shefield Online Papers in Social Research

12. Karsten L, Pel E (2000). kateboarders exploring urban public space: Ollies, obstacles and conflicts. Journal of Housing and the Built Environment 15: 327-340

13. Kiewa J (2001). Control over self and space in rockclimbing. Journal of Leisure Research 33: 363-382

14. Kiewa J (2002). Traditional climbing: metaphor of resistance or metanarrative of oppression? Leisure Studies 21:
145-161

15. Lopes J (2000) A Cidade e a Cultura. Um estudo sobre práticas culturais urbanas. Edições Afrontamento, Porto

16. Maffesoli M (2004). Société ou communauté. Tribalisme et sentiment d'appartenance. Corps et Culture

17. Muggleton D (2005). From classlessness to clubculture. A genealogy of post-war British youth cultural analysis. Young Nordic Journal of Youth Research 13: 205-219

18. Pais J (1996). Culturas Juvenis. Imprensa Nacional-Casa da Moeda, Lisboa

19. Pais J (2005). Jovens e cidadania. Sociologia, Problemas e práticas 2005: 53-70

20. Ruquoy D (1997). Situação de entrevista e estratégia do investigador. In: L. Albarello et al (ed) Práticas e métodos de investigação em Ciências Sociais. Gradiva, Lisboa, pp 84-116

21. Simões J (2001). Globalização e consumo. Reavaliando o conceito de audiência. O caso das (sub)culturas juvenis. In: F. Cádima, J. Rosa (eds) Revista de Comunicação e Linguagens - POP. Relógio D' Água, Lisboa, pp 77-106

22. Steyn D (2004). The Body in Public Culture: Skateboarder. Postamble 1: 12-18

23. Thornton S (1997). General introduction. In: K. Gelder, S. Thornton (eds) The subcultures reader. Routledge, London, pp 1-11

24. Vala J (1986) A análise de conteúdo. In: Santos Silva A, Madureira Pinto J (eds) Metodologia das Ciências Sociais. Edições Afrontamento, Porto, pp 101-128

25. Volosinov V (1973). Marxism and the Philosophy of Language. Seminar Press, New York

26. Williams J (2006). Authentic identities. Straightedge subculture, music, and the internet. Journal of Contemporary Ethnography 35: 173-200

27. Williams J (2007) Youth subcultural studies: sociological traditions and core concepts. Sociology Compass 1: 572-593

28. Willis P (1978) Profane Culture. Routledge \& Kegan Paul., London 